\title{
REVIEW PAPER ON “ON ROAD VEHICLE BREAKDOWN ASSISTANCE SYSTEM"
}

\author{
Prof. MS. Pranita P. Deshmukh, Mr. Yash S. Puraswani, Mr. Aditya D. Attal, Mr. Prasad G. Murhekar, \\ Mr. Vivek A. katole, Mr. Vidhitya M. Wankhade \\ Department of Computer Science \& Engineering \\ Prof. Ram meghe institute of technology and research \\ Anjangaon Bari Rd, Badnera, Amravati, Maharashtra 444701
}

\begin{abstract}
Nowadays people prefer own vehicle for travelling to avoid rush and inconvenience. But in case of any breakdown during journey, it is very difficult to search mechanic in unknown place. Therefore, to sort out this problem we proposed a mobile as well as web based assistance system. In this system all mechanics will be able to register themselves with their service details. On the other hand, the end user has to download and install mobile assistance application in their android mobile. The mobile app will track user's current location automatically when he is online and store in database. On the basis of user's current location, system will prepare a list of nearest service providers and the list will be stored in users mobile. When the user search for the service provider then the list will be displayed and as it is stored in user mobile, so that if user's vehicle breakdown and if his mobile is out of range, then also he will be able to view service providers nearest to previous location that was tracked by the system
\end{abstract}

Keywords - Vehicle, Service providers, Breakdown, Assistance.

\section{INTRODUCTION}

As everything is going online but still some rural areas are existing where internet is not accessible. If someone's vehicle breakdown suddenly on any village road, it will be very difficult for him to handle that situation without mobile phone and internet. (Singh, Kapoor Kaushik, Maringanti, 2010) Therefore, to solve such types of issues, we proposed online assistance system which will keep a track of user's location and store nearest service providers list offline. So that if internet range is not available at any location, then also user will be able to view nearest service providers for last recorded location.

Along with assistance, we proposed review analysis module in this project. In review analysis, customers will submit their reviews about service of service provider and the proposed module will find out the polarity of submitted text. For review analysis we will make use of WORDNET dictionary which is available online.

(George, Beckwith, Christiane, Derek, and Katherine ,1993) WordNet is a lexical database for the English language. It groups English words into sets of synonyms called synsets, provides short definitions and usage examples, and records a number of relations among these synonym sets or their members. WordNet can thus be seen as a combination of dictionary and thesaurus. Along with WordNet we will use NLP for keywords extraction from submitted reviews. NLP (Natural language processing) is a subfield of linguistics, computer science, information engineering, and artificial intelligence concerned with the interactions between computers and human languages, in particular how to program computers to process and analyze large amounts of natural language data.

\section{LITERATURE REVIEW}

The recent technological advancement in the field of mobility has impressed the current society tremendously. (Haridas, Baharudin, \& karkonasasi ,2016) Based on AAM annual report, statistic shows that around $70 \%$ of service is resolved immediately which is classified as minor failure breakdown issue. Minor failure breakdown has segregated into several categories like engine failure start up, engine failure heat, lockout, and others. This statistic is only from single organization apart from the other services available nationwide. This clearly shows that the number of vehicles encountering such emergency situation requires the service to be available. (Haridas, Baharudin, \& karkonasasi ,2016) Firstly, the existing manual process is not able to address the transaction request effectively. The manual process is holding back staff as they are unable to provide quick response due to lack of streamlined system with sufficient information available. Secondly, quick responses features are insufficient in the existing products. This limits a quick response for the consumer when there is an emergency request. In the existing products, the emergency request is being handled by the call center hotline as an interim person before reaching the vendors. This causes the consumers to experience slow responses due to long waiting hours at the call

center. (Kumaar.D, Balakrishna, Subha, Harin. K, 2019) Akhila V Khanapuri et al (2015) proposed that there has been an exponential increase in the number of cars on road, number of road accidents and vehicle breakdown cases recorded. Finding effective ways to achieve maximum fuel efficiency 


\section{International Journal of Engineering Applied Sciences and Technology, 2020 \\ Vol. 4, Issue 11, ISSN No. 2455-2143, Pages 199-202 \\ Published Online March 2020 in IJEAST (http://www.ijeast.com)}

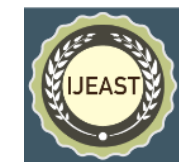

without hampering the internal structure of these vehicles along with providing a response system to combat mishaps is a challenging task. Main objective is to design a system that can be easily installed and to provide platform for fast access.

\section{PROPOSED SYSTEM}

\section{A. Existing System}

In existing system, result of the search is available only when the user is in the range, so it is very difficult for the user to get the service especially in rural areas. Assistance through helpline is highly prone to unavailability that makes the travelers experience worse.

\section{B. System objectives}

- To develop a web based service provider Registration system

- To implement recommendation system on the basis of user ratings

- To implement review analysis module using Text mining technique

- To develop android app for service provider searching.

\section{Advantage of Proposed System}

The traveler is provided with more services and support to ensure that they have a good travelling experience. The traveler can have easy access to the services based on the current location using Google Maps Navigation System. The services are provided in a wide range so that travelers enjoy the maximum benefit out of it. System recommends traveler to choose the best service.

\section{System Architecture}

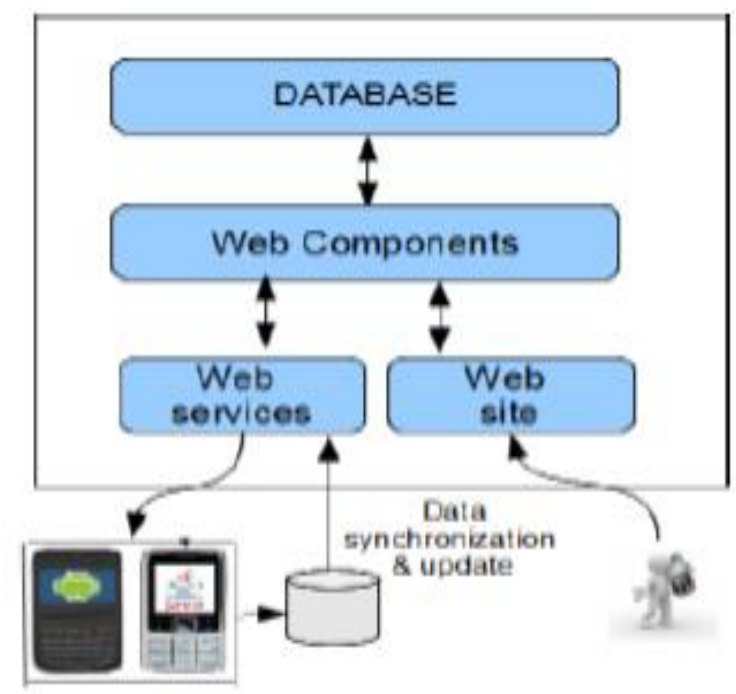

\section{SYSTEM REQUIREMENT \& TECHNOLOGY}

- Deployment Platform: Windows

- Application Server: JBoss AS7/Apache Tomcat/Glassfish

- Technology: Java EE

- Development Tools (Server side): Servlets \& JSP, Java Beans

- $\quad$ MVC framework: Hibernate

- Database technologies: MySQL, JDBC

- Web Development: XML, HTML, DHTML, JavaScript, AJAX

- Development Tool: Eclipse IDE

\section{SYSTEM DEVELOPMENT}

\section{A. Admin Panel}

Admin Panel is the top-most module which allows the system administrator to login to the system.

Admin can approve or decline the requests that are pending of various service providers. Admin can also see the list of service provider that are registered in the system, and review their ratings.

\section{B. Service provider}

This module allows the service providers to register themselves to the system. As soon as the admin accepted the request of service provider, that service provider is available to customer for service. Service providers can also manage services and profile details. When the customer sends the request to the particular service provider, service provider can contact with the customer who sent the request.

\section{End user}

Normal users can request for service through android app, users can search the nearest service providers and contact with them.

\section{Recommendation}

Recommendation will be given on the basis of ratings and reviews given by customers

\section{E. Review analysis}

This module Specify reviews of registered service providers. System detects the negative words using NLP and replace the negative words with their synonyms. polarity detection using WordNet dictionary, it can be positive, negative or neutral.

\section{F. Android App}

This module is available to normal users of the system, who can login into the app. App also provides offline service provider recommendations. When the internet is available 


\section{International Journal of Engineering Applied Sciences and Technology, 2020 \\ Vol. 4, Issue 11, ISSN No. 2455-2143, Pages 199-202 \\ Published Online March 2020 in IJEAST (http://www.ijeast.com)}

location is track using GPS and generates the report of available service provider in nearest areas.

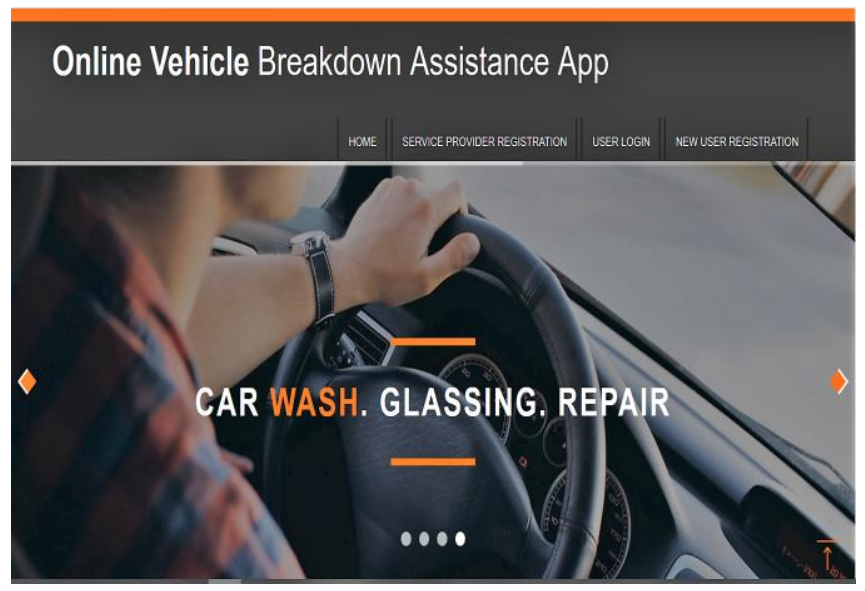

Fig:1 Home page

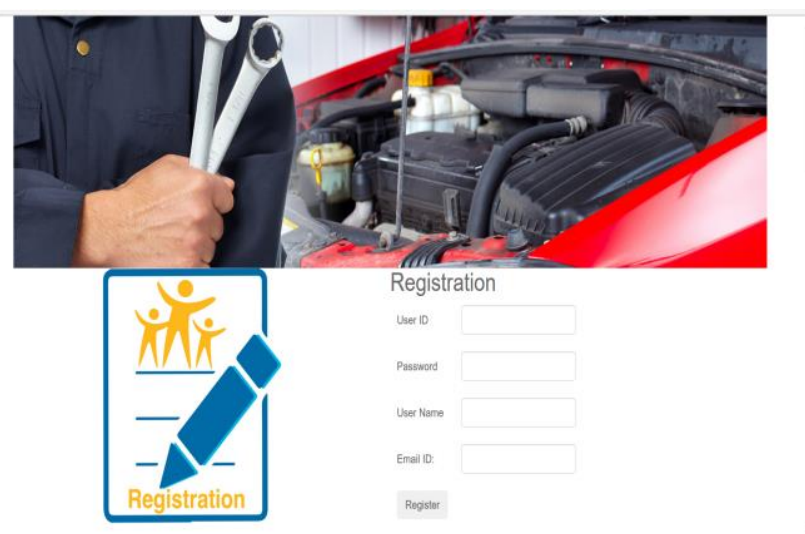

Fig:2 It allows user to register their details in order to get access of the application.

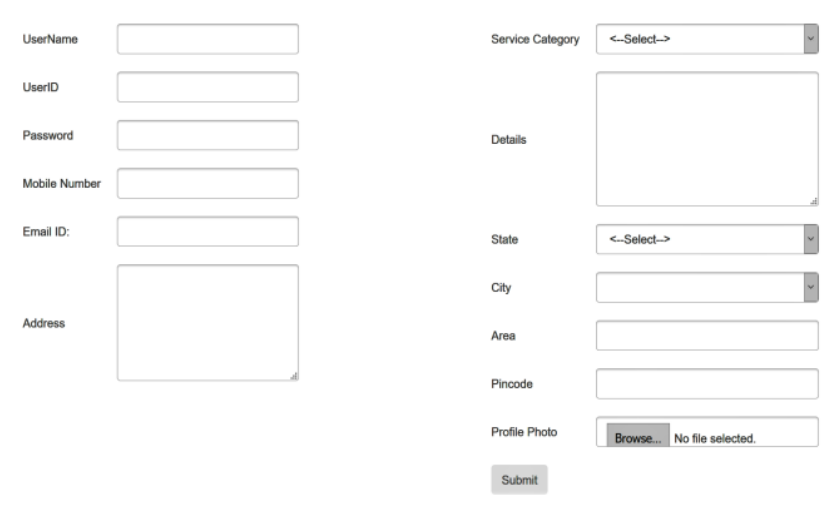

Fig:3 It allows user to enter details manually for searching the nearest service providers.

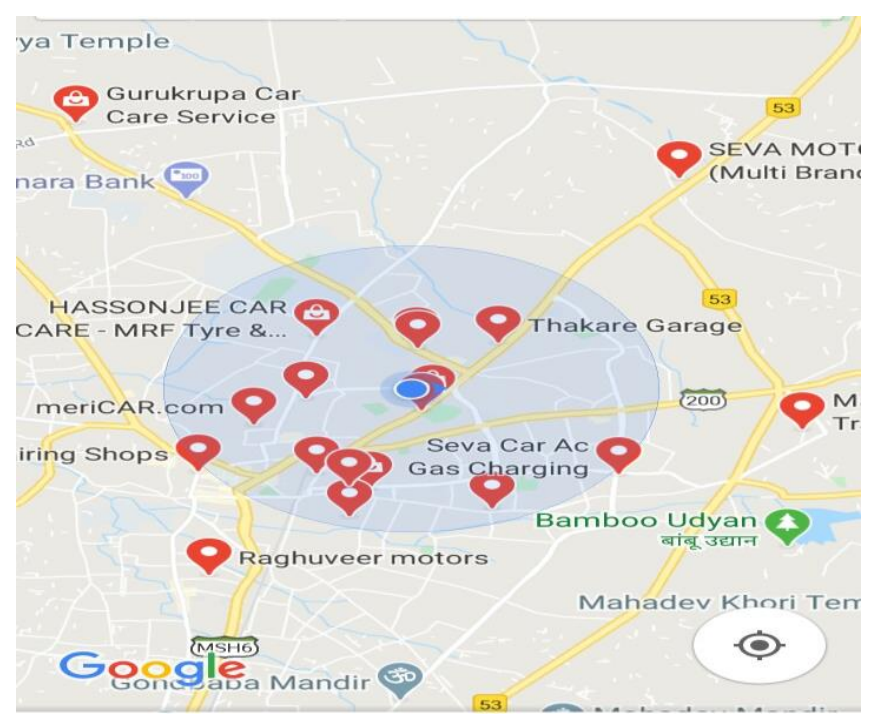

Fig:4 It display the search result.

\section{CONCLUSION}

Thus our emergency breaks down service give better location result. Our application easily identifies the nearby location which is very useful to the user who uses it in emergency needs. It also has offline feature that provide recommendations when internet is not connected. This approach makes the user experience very easy and performs better than the existing system in crucial times.

\section{REFERENCE}

[1] Bo Pang., and Lillian Lee. (2004)'. A sentimental education: Sen- timent analysis using subjectivity summarization based on minimum cuts. In Proceedings of the 42nd annual meeting on Association for Computational Linguistics, (page 271).

[2] Ziebinski A., Cupek R., Grzechca D., and chruszczyk L. (2017)'. Review of advance driver assistance system (ADAS) (DOI: 10.1063/1.5012394).

[3] Singh Puneet, Kapoor Ashutosh, Kaushik Vishal, and Bindu Hima. (2010)'. Architecture for auto- mated tagging and clustering of song_les according to mood. International Journal of Computer Science Is- sues (IJCSI), 7(4).

[4] Jin Wei. (2008)'. Mining hidden associations in text corpora through concept chain and graph queries. ProQuest,

[5] Thayer Robert. (1989)'. The biopsychology of mood and arousal. Oxford University Press.

[6] Neviarouskaya A., Prendinger H., and Ishizuka, M (2009)'. Semantically distinct verb classes involved in sentiment analysis. In: Proceedings of the International Conference on Applied Computing (AC 2009), Japan, (pp. 27-34).

[7]" Haridas K, Ahmad S. Baharudin, Kamal \& karkonasasi (2016)'. Automotive Servicing and Breakdown Assistance System (ASBAS): Impact of Perceived Ease of Use (PEOU) 
and Vehicle Breakdown Servicing Necessity (VBSN) on Vendor's Intention to Adopt ASBAS."

[8]" Kumaar.A, Balakrishna, Subha. S, Harin. K (2019)'. On Road Vehicle Service finder."

[9]" Kapadi V., Guruju S., \& Bojja B. (2017)'. Emergency Breakdown Services using Android Application."

[10] Miss K Iswarya, Miss. D. Devika, and MR. E. Ranjith. (2010)'. Road Assistance System using GPS. International Journal of Advance Research, Ideas and Innovations in Technology (IJARIIT).

[11] George A., Beckwith R., Christiane F., Derek G., and Katherine M. (1993)'. Introduction to WordNet: An on-line Lexical Database (pg 1-5).

[12] Wang W., Chen H., and Bell M. (2005)'. Vehicle Breakdown Duration Modelling 